\title{
Stereoselective synthesis, X-ray analysis, computational studies and biological evaluation of new thiazole derivatives as potential anticancer agents
}

\author{
Yahia N. Mabkhot ${ }^{1 *}$ (D), Mohammed M. Alharbi', Salim S. Al-Showiman' ${ }^{1}$, Hazem A. Ghabbour ${ }^{2,3}$, \\ Nabila A. Kheder ${ }^{4,5}$, Saied M. Soliman ${ }^{6,7}$ and Wolfgang Frey ${ }^{8}$
}

\begin{abstract}
Background: The synthesis of new thiazole derivatives is very important because of their diverse biological activities. Also, many drugs containing thiazole ring in their skeletons are available in the market such as Abafungin, Acotiamide, Alagebrium, Amiphenazole, Brecanavir, Carumonam, Cefepime, and Cefmatilen.

Results: Ethyl cyanoacetate reacted with phenylisothiocyanate, chloroacetone, in two different basic mediums to afford the thiazole derivative $\mathbf{6}$, which reacted with dimethylformamide- dimethyl acetal in the presence of DMF to afford the unexpected thiazole derivative 11. The structures of the thiazoles $\mathbf{6}$ and $\mathbf{1 1}$ were optimized using B3LYP/6$31 \mathrm{G}(\mathrm{d}, \mathrm{p})$ method. The experimentally and theoretically geometric parameters agreed very well. Also, the natural charges at the different atomic sites were predicted. HOMO and LUMO demands were discussed. The anticancer activity of the prepared compounds was evaluated and showed moderate activity.

Conclusions: Synthesis of novel thiazole derivatives was done. The structure was established using X-ray and spectral analysis. Optimized molecular structures at the B3LYP/6-31G(d,p) level were investigated. Thiazole derivative $\mathbf{1 1}$ has more electropositive S-atom than thiazole 6 . The HOMO-LUMO energy gap is lower in the former compared to the latter. The synthesized compounds showed moderate anticancer activity.
\end{abstract}

Keywords: Thiazoles, X-ray crystallography, Computational studies, DMF-DMA, Cytotoxic activity

\section{Introduction}

Currently marketed anticancer medications have increasing problems of various toxic side effects and development of resistance to their action. So, there is an urgent clinical need for the synthesis of novel anticancer agents that are potentially more effective and have higher safety profile. The synthesis of different thiazole derivatives has attracted great attention due to their diverse biological activities that include anticonvulsant [1, 2], antimicrobial [3, 4], anti-inflammatory $[5,6]$, anticancer [7], antidiabetic [8], anti-HIV [9], anti-Alzheimer [10], antihypertensive [11], and antioxidant activities

\footnotetext{
${ }^{*}$ Correspondence: yahia@ksu.edu.sa

1 Department of Chemistry, College of Science, King Saud University, P. O. Box 2455, Riyadh 11451, Saudi Arabia

Full list of author information is available at the end of the article
}

[12]. The reaction between active methylene compounds with phenylisothiocyanate and $\alpha$-haloketones in DMF in the presence of potassium hydroxide is the simple and convenient method for the synthesis of many thiazole derivatives [13-15]. In continuation of our interest in the synthesis of new biologically active heterocyclic rings [16-22] and motivated by these information, it was thought worthwhile to synthesize some novel thiazole derivatives and to test their antitumor activity in order to discover new potentially biologically active drugs of synthetic origin.

\section{Results and discussion \\ Chemistry}

The thiazole derivative 6 was previously obtained by the reaction of ethyl cyanoacetate with phenylisothiocyanate 
and propargyl bromide in DMF-NaH [23]. The presence of many functional groups attached to this bioactive thiazole ring motivated us to prepare it again to use it as a precursor for some new heterocycles bearing the bioactive thiazole ring. In this research, we used, instead of propargyl bromide, other reagents, such as chloroacetone, and we studied the configuration of the isolated products.

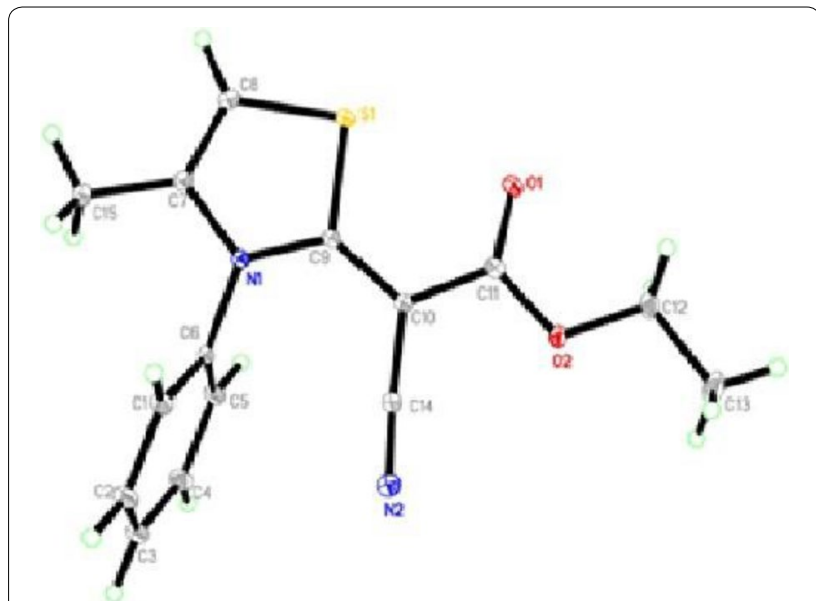

Fig. 1 ORTEP diagram of the thiazole $\mathbf{6}$. Displacement ellipsoids are plotted at the $40 \%$ probability level for non-H atoms
The reaction of ethyl cyanoacetate with phenylisothiocyanate and chloroacetone in DMF- $\mathrm{K}_{2} \mathrm{CO}_{3}$ or sodium ethoxide solution afforded only one isolable product. The isolated product was identified as $(Z)$-ethyl 2-cyano-2-(4methyl-3-phenylthiazol-2(3H)-ylidene) acetate (6). Its structure was established from X-ray analysis (Fig. 1) [24] and was confirmed using elemental and spectral analysis (IR, ${ }^{1} \mathrm{H}$ NMR, ${ }^{13} \mathrm{C}$ NMR). The suggested mechanism for the synthesis of thiazole 6 is outlined in Scheme 1.

The configuration of thiazole $\mathbf{6}$ was confirmed using X-ray analysis (Figs. 1, 2).

Next, fusion of thiazole 6 with DMF-DMA in presence of DMF afforded the unexpected thiazole derivative $\mathbf{1 1}$ (Scheme 2). The structure of the isolated product was elucidated based on its elemental and spectral analysis (IR, NMR, MS and X-ray) (see "Experimental section") (Figs. 3, 4).

In many reports dimethylformamide were used as a formylating agent for indole [25], thiophene [26], and substituted benzene [27]. Based on these information, we suggested that the reaction was started via formylation of thiazole derivative 6 by DMF to afford the formyl derivative 7 , which involved a reversible opening of the thiazole ring to give intermediate $\mathbf{8}$. The subsequent cyclization of $\mathbf{8}$ afforded $\mathbf{9}$, which underwent dehydration to give the methyl ketone 10. Reaction of intermediate $\mathbf{1 0}$ with dimethylformamide-dimethylacetal
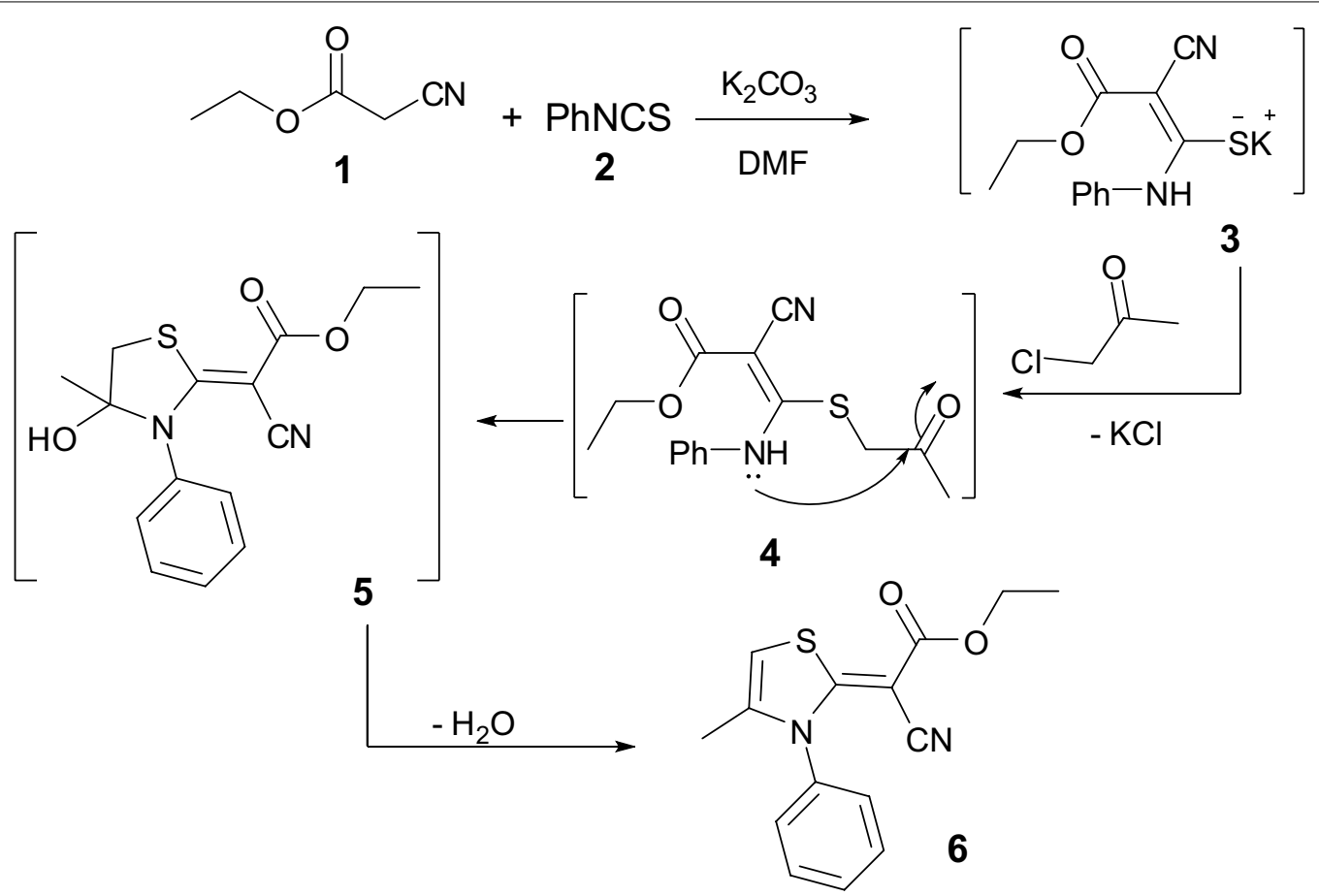

Scheme 1 Synthesis of (Z)-ethyl 2-cyano-2-(4-methyl-3-phenylthiazol-2(3H)-ylidene) acetate (6) 


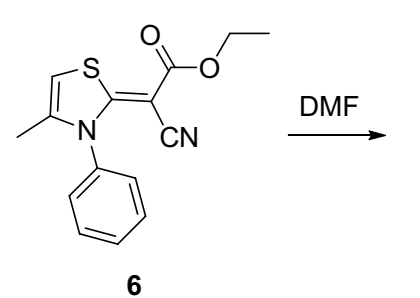<smiles>CCOC(=O)/C(C#N)=C1\SC(C=O)=C(C)N1c1ccccc1</smiles><smiles>CC(C)C</smiles>

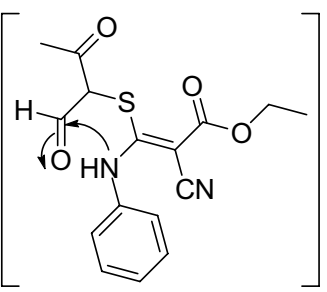
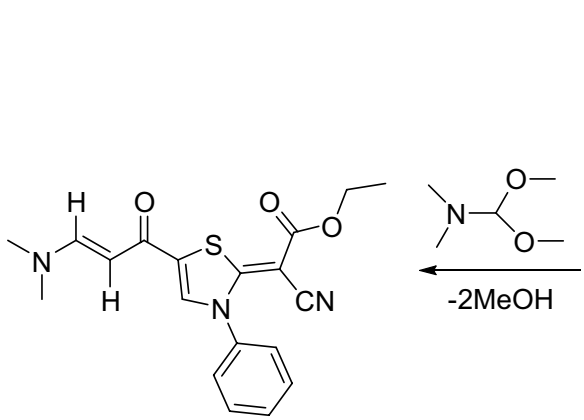<smiles>CCOC(=O)/C(C#N)=C1\SC(C(C)=O)=CN1c1ccccc1</smiles>
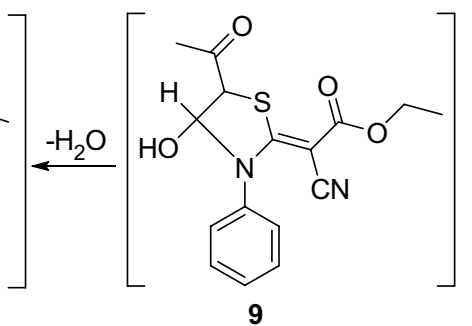

11

Scheme 2 A suggested mechanism for the synthesis of thiazole derivative $\mathbf{1 1}$

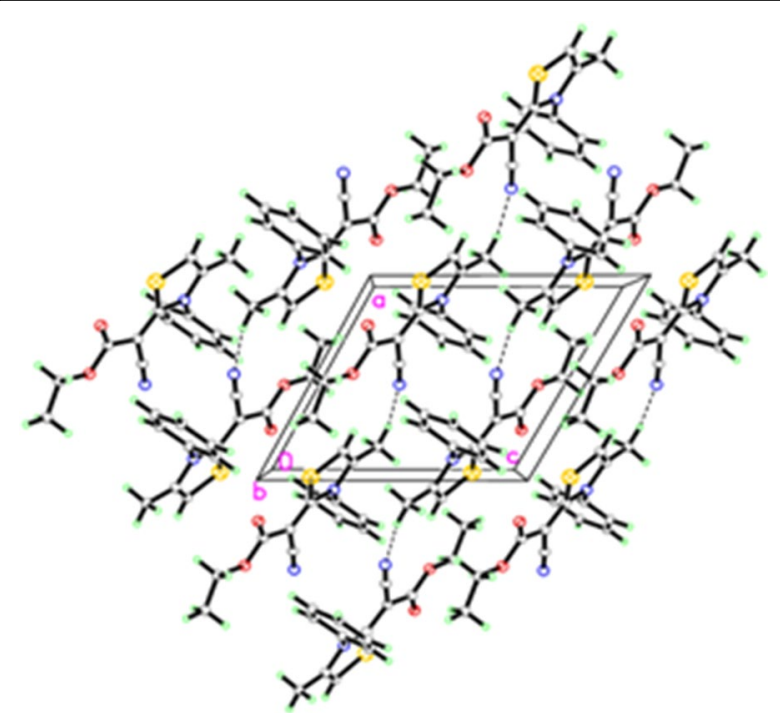

Fig. 2 Molecular packing of thiazole $\mathbf{6}$ viewed hydrogen bonds which are drawn as dashed lines along $a$ axis

(DMF-DMA) afforded the unexpected thiazole derivative 11 (Scheme 2).

For more details see (Additional file 1: Tables S1-S6) (these files are available in the ESI section).

\section{Geometry optimization}

The optimized molecular geometries of the thiazole derivatives $\mathbf{6}$ and $\mathbf{1 1}$ are shown in Fig. 5 and the results of the calculated bond distances and angles are given in Additional file 1: Table S7. Good correlations were obtained between the calculated and experimental bond distances with correlation coefficients ranging from 0.991 to 0.996 (Fig. 6). The maximum differences between the calculations and experiments not exceed $0.03 \AA$ for both compounds indicating the well prediction of the molecular geometries.

\section{Charge population analysis}

The natural population analysis is performed to predict the natural charges (NC) at the different atomic sites (Additional file 1: Table S8). The ring sulphur atom has natural charge of 0.5079 and 0.5499 e for thiazole 6 and thiazole 11, respectively. In both cases, the S-atoms have electropositive nature where higher positive charge is found in thiazole $\mathbf{1 1}$ probably due to the presence of carbonyl group as electron withdrawing group directly attached to the ring while in thiazole $\mathbf{6}$, there is one methyl as electron releasing group via inductive effect attached to the ring. The negative sites are related to the nitrogen and oxygen sites as also further confirmed from the molecular electrostatic potential (MEP) maps shown in Fig. 7.

\section{Frontier molecular orbitals}

The HOMO and LUMO levels of the thiazole derivatives 6 and $\mathbf{1 1}$ are shown in Fig. 8. The HOMO and LUMO energies of thiazole 6 are -5.3582 and $-0.8765 \mathrm{eV}$, respectively while for thiazole $\mathbf{1 1}$ are -5.3210 and 


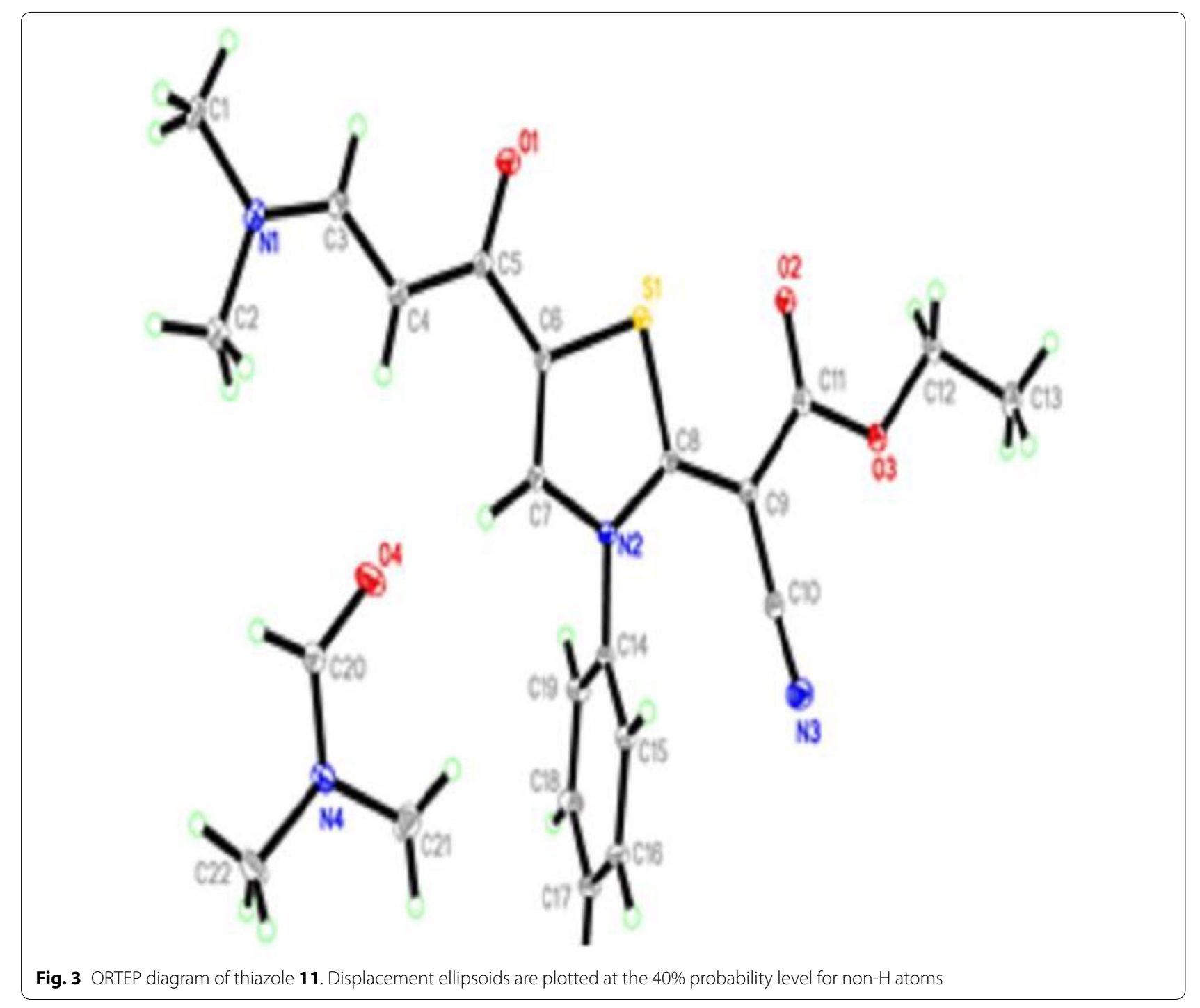

$-1.5715 \mathrm{eV}$, respectively. As a result, the HOMO-LUMO energy gap is calculated to be 4.4818 and $3.7495 \mathrm{eV}$ for compounds 6 and 11, respectively. The HOMO and LUMO are mainly localized over the thiophene ring, $\mathrm{C} \equiv \mathrm{N}$ and $\mathrm{C}=\mathrm{O}$ groups for both compounds. Since the HOMO and LUMO levels are mainly located over the $\pi$-system of the studied compound so the HOMOLUMO intramolecular charge transfer is mainly a $\pi-\pi^{*}$ transition.

\section{Cytotoxic activity}

The anti-cancer activity of the thiazole derivatives $\mathbf{6}$ and 11 was determined against the Human Colon Carcinoma (HCT-116) cell line in comparison with the anticancer drug vinblastine, using MTT assay [28, 29]. The cytotoxic activity was expressed as the mean $\mathrm{IC}_{50}$ (the concentration of the test compounds required to kill half of the cell population) of three independent experiments (Table 1). The results revealed that thiazole $\mathbf{1 1}$ has moderate anticancer activity against colon carcinoma (HCT-116), while thiazole 6 has less activity.

\section{Experimental section \\ Chemistry \\ General}

All the melting points were measured on a Gallen Kamp apparatus in open glass capillaries and are uncorrected. The IR Spectra were recorded using Nicolet 6700 FT-IR 


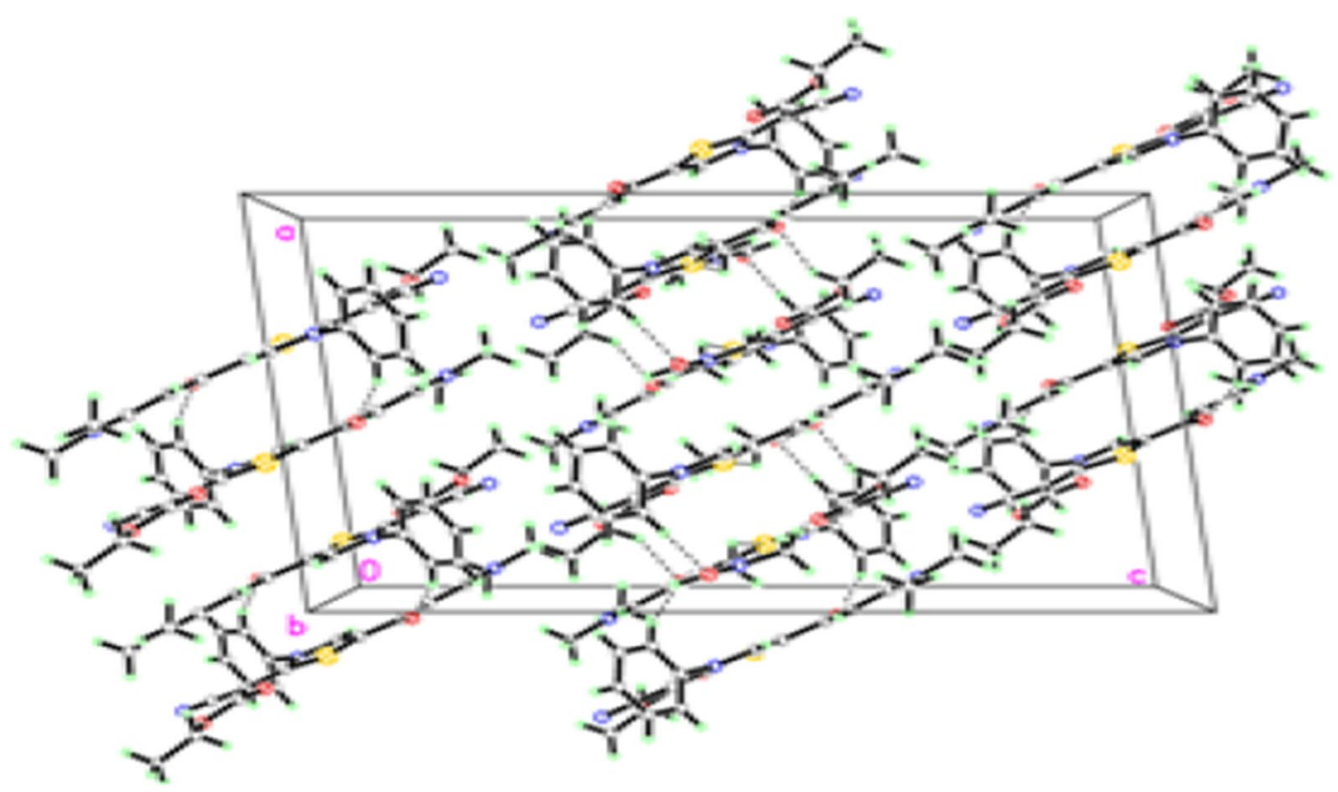

Fig. 4 Molecular packing of thiazole $\mathbf{1 1}$ viewed hydrogen bonds which are drawn as dashed lines

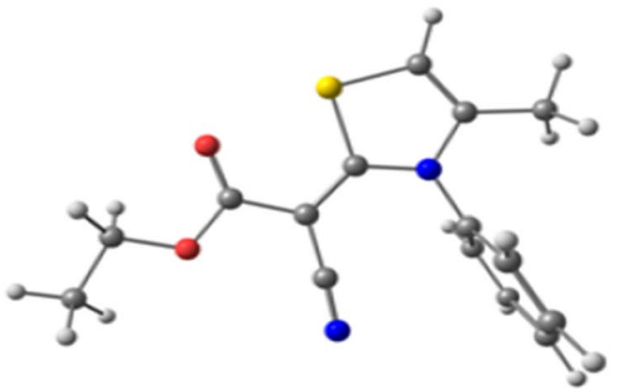

Thiazole 6

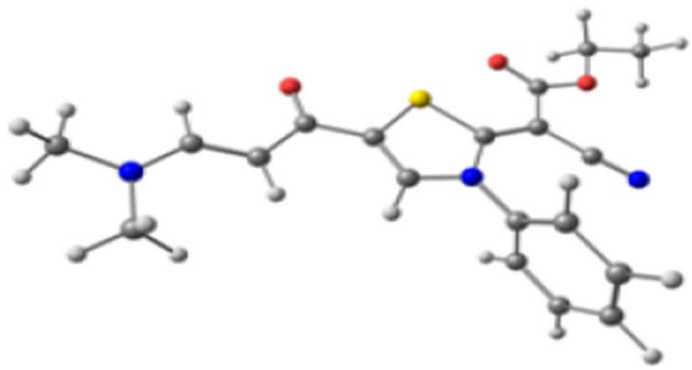

Thiazole 11

Fig. 5 The optimized structure of the thiazoles $\mathbf{6}$ and $\mathbf{1 1}$

spectrophotometer. ${ }^{1} \mathrm{H}$ - and ${ }^{13} \mathrm{C}-\mathrm{NMR}$ spectra were recorded on a JEOL ECP 400 NMR spectrometer operating at $400 \mathrm{MHz}$ in deuterated chloroform $\left(\mathrm{CDCl}_{3}\right)$ as solvent and TMS as an internal standard; chemical shifts $\delta$ are expressed in ppm units. Mass spectra were recorded on a Shimadzu GCMS-QP 1000 EX mass spectrometer (Tokyo, Japan) at $70 \mathrm{eV}$. Elemental analysis was carried out on a 2400 CHN Elemental Analyzer. The single-crystal X-ray diffraction measurements were accomplished on a Bruker SMART APEX II CCD diffractometer. The biological evaluations of the products were carried out in the Medical Mycology Laboratory of the Regional Center for Mycology and Biotechnology of Al-Azhar University, Cairo, Egypt.

\section{Synthesis of (Z)-ethyl}

2-cyano-2-(4-methyl-3-phenylthiazol-2(3H)-ylidene)acetate (6)

\section{Method A}

To a stirred solution of ethyl cyanoacetate (1.13 g, $1.07 \mathrm{~mL}, 10 \mathrm{mmol})$, in dimethylformamide $(10 \mathrm{~mL})$ was added potassium carbonate $(1.38 \mathrm{~g}, 10 \mathrm{mmol})$. Stirring was continued at room temperature for $30 \mathrm{~min}$, then phenylisothiocyanate $(1.35 \mathrm{~g}, 1.2 \mathrm{~mL}, 10 \mathrm{mmol})$ was added dropwise to this mixture and stirring was continued for another $1 \mathrm{~h}$. To this reaction mixture, chloroacetone $(0.92 \mathrm{~g}, 0.8 \mathrm{~mL}, 10 \mathrm{mmol})$ was added and the mixture was stirred for additional $3 \mathrm{~h}$ at room 


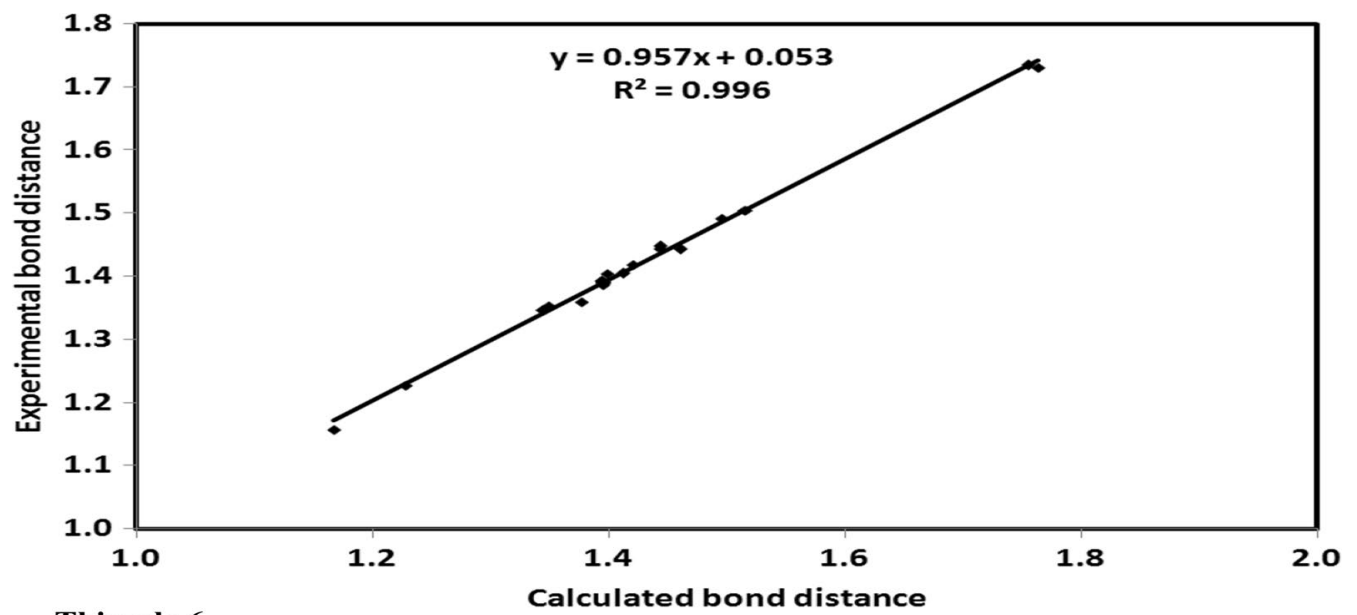

Thiazole 6

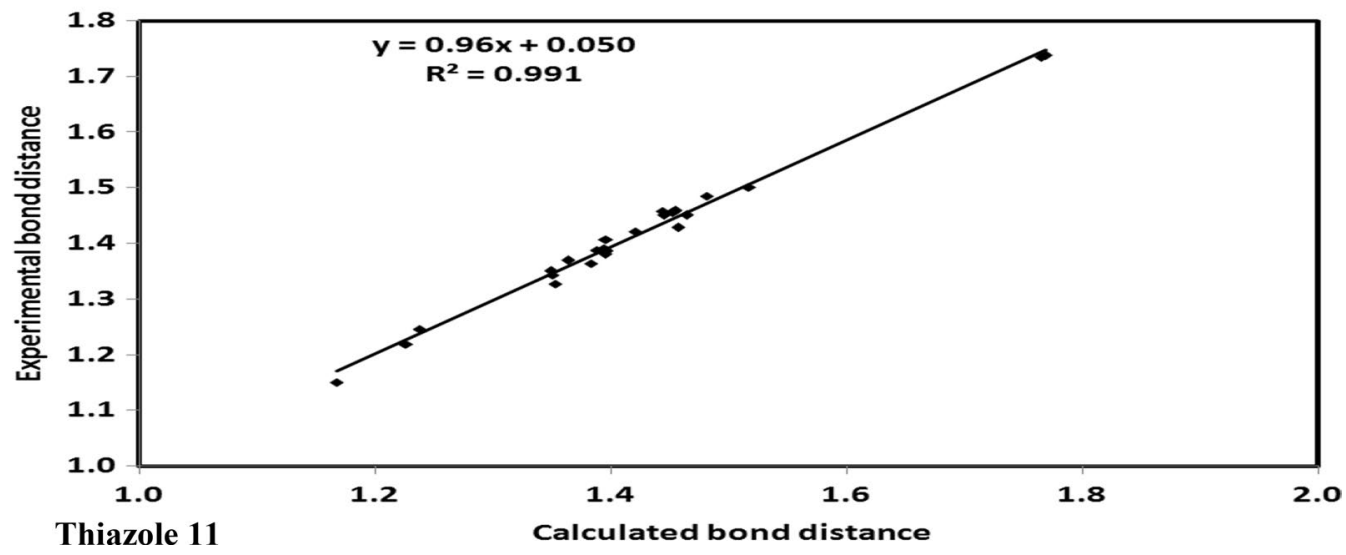

Fig. $\mathbf{6}$ The correlations between the calculated and experimental bond distances of the thiazoles $\mathbf{6}$ and $\mathbf{1 1}$

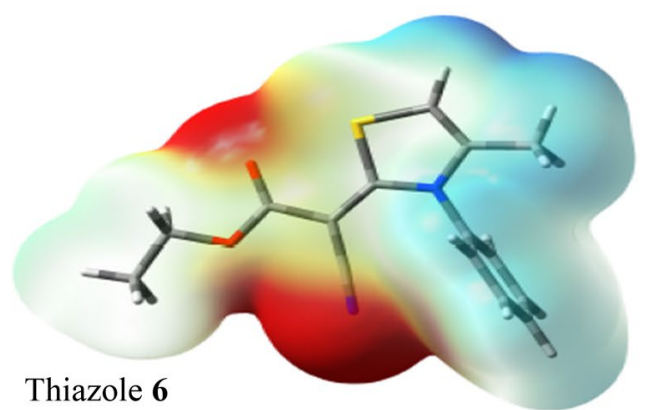

Thiazole 6

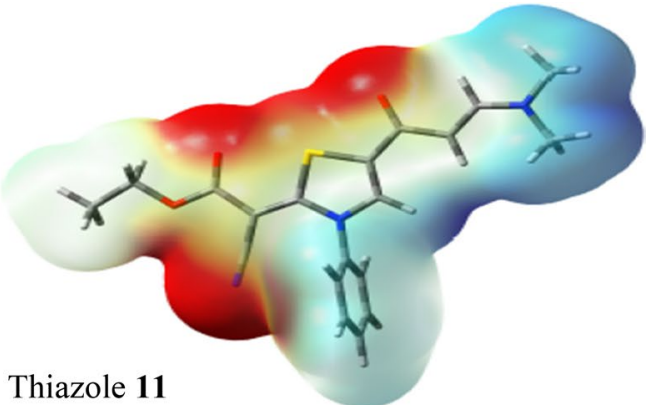

Fig. $\mathbf{7}$ The MEP figure of the thiazoles $\mathbf{6}$ and $\mathbf{1 1}$ 


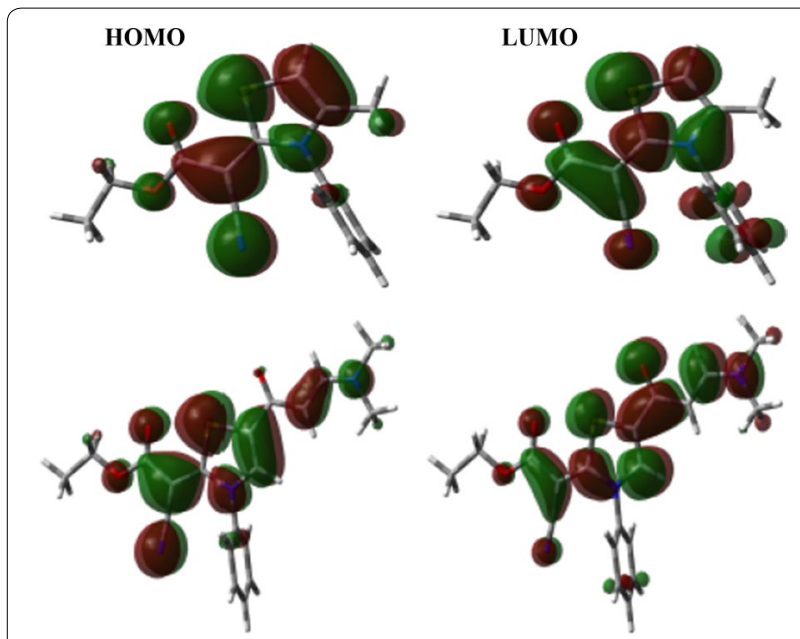

Fig. 8 The frontier molecular orbitals of the synthesized compounds $\mathbf{6}$ and $\mathbf{1 1}$ calculated at the B3LYP/6-31G(d,p) level

temperature. Finally, the content was poured on cold water $(50 \mathrm{~mL})$. The crude solid product was filtered off and recrystallized from DMF, yield $85 \%$, mp. $215{ }^{\circ} \mathrm{C}$ [lit $\mathrm{mp}$ [23]. $\left.190{ }^{\circ} \mathrm{C}\right]$; IR (KBr) $\mathrm{v}_{\max } 1680(\mathrm{CO}), 2214(\mathrm{C} \equiv \mathrm{N})$, 2988 (aliphatic, $\mathrm{CH}$ ), 3281(aromatic, $\mathrm{CH}$ ) $\mathrm{cm}^{-1}$; ${ }^{1} \mathrm{H}$ NMR $\left(400 \mathrm{MHz}, \mathrm{CDCl}_{3}\right): \delta 1.19\left(\mathrm{t}, 3 \mathrm{H} . \mathrm{CH}_{3}, J=7.2 \mathrm{~Hz}\right), 1.84(\mathrm{~s}$, $\left.3 \mathrm{H}, \mathrm{CH}_{3}\right), 4.15$ (q, 2H, $\left.\mathrm{CH}_{2}, J=7.2 \mathrm{~Hz}\right), 6.39$ (s, 1H. 5-H), 7.20-7.55 (m, 5H, Ar-H); ${ }^{13} \mathrm{C}$ NMR (100 MHz, $\left.\mathrm{CDCl}_{3}\right): \delta$ 14.46, 29.59, 60.48, 66.36, 105.62, 115.22, 128.72, 129.88, $131.07,136.26,138.45,167.94,168.05$. Anal. calcd. for $\mathrm{C}_{15} \mathrm{H}_{14} \mathrm{~N}_{2} \mathrm{O}_{2} \mathrm{~S}: \mathrm{C}, 62.92 ; \mathrm{H}, 4.93 ; \mathrm{N}, 9.78$ Found: C, 62.89; $\mathrm{H}, 4.88$; N, 9.79 .

\section{Method B}

A mixture of ethyl cyanoacetate $(1.13 \mathrm{~g}, 1.07 \mathrm{~mL}$, $10 \mathrm{mmol})$ in sodium ethoxide $(0.23 \mathrm{~g}$ Sodium in $10 \mathrm{ml}$ of absolute ethanol) was stirred for $10 \mathrm{~min}$. To this mixture, phenyl isothiocyanate $(1.35 \mathrm{~g}, 10 \mathrm{mmol})$ was added dropwise and the mixture was stirred for another $1 \mathrm{~h}$. Chloroacetone $(0.92 \mathrm{~g}, 0.8 \mathrm{~mL}, 10 \mathrm{mmol})$ was added to the reaction mixture and stirring was continued for $3 \mathrm{~h}$. Finally, it was poured on cold water and the solid precipitate that formed was filtered and recrystallized from DMF to afford the same product which obtained from method A, yield 65\%.

\section{Synthesis of (Z)-ethyl 2-cyano-2-(5-((E)-3-(dimethylamino) acryloyl)-3-phenyl thiazol-2(3H)-ylidene)acetate (11)}

A mixture of thiazole 6 (2.86 g, $10 \mathrm{mmol})$ and DMFDMA (1.19 g, $1.33 \mathrm{~mL}, 10 \mathrm{mmol})$ in DMF (3 mL) was heated on a water bath for $1 \mathrm{~h}$, then left to cool to room temperature. The precipitated solid filtered off, washed with $\mathrm{EtOH}$ and recrystallized from DMF to afford the thiazole derivative 11 in $82 \%$ yield, m.p. $260{ }^{\circ} \mathrm{C}$; IR ( $\left.\mathrm{KBr}\right)$ $\mathrm{v}_{\max } 1669(\mathrm{C}=\mathrm{O}), 2189(\mathrm{C} \equiv \mathrm{N}), 2928$ (aliphatic, $\left.\mathrm{CH}\right)$, 3056 (aromatic, $\mathrm{CH}$ ) cm ${ }^{-1}$; ${ }^{1} \mathrm{H}$ NMR (400 MHz, $\mathrm{CDCl}_{3}$ ): $\delta 1.26\left(\mathrm{t}, 3 \mathrm{H} . \mathrm{CH}_{3}, J=7.3 \mathrm{~Hz}\right), 2.88\left(\mathrm{~s}, 3 \mathrm{H}, \mathrm{CH}_{3}\right), 3.16(\mathrm{~s}$, $\left.3 \mathrm{H}, \mathrm{CH}_{3}\right), 4.21\left(\mathrm{q}, 2 \mathrm{H}, \mathrm{CH}_{2}, J=7.3 \mathrm{~Hz}\right), 5.28(\mathrm{~d}, 1 \mathrm{H}, \mathrm{CH}$, $J=12.5 \mathrm{~Hz}$ ), 7.43-7.56 (m, 7H, Ar-H); MS m/z (\%) 369 $\left(\mathrm{M}^{+}, 23.78\right), 299$ (0.98), 271(1.36), 98 (100), 77 (10.05), 70 (7.8). calcd. for $\mathrm{C}_{19} \mathrm{H}_{19} \mathrm{~N}_{3} \mathrm{O}_{3} \mathrm{~S}: \mathrm{C}, 61.77 ; \mathrm{H}, 5.18 ; \mathrm{N}, 11.37$. Found: $61.82 ; \mathrm{H}, 5.21 ; \mathrm{N}, 11.28$.

\section{X-Ray analysis}

The thiazoles of $\mathbf{6}$ and $\mathbf{1 1}$ were obtained as single crystals by slow evaporation from DMF solution of the pure compound at room temperature. Data were collected on a BrukerAPEX-II D8 Venture area diffractometer, equipped with graphite monochromatic Mo $K \alpha$ radiation, $\lambda=0.71073 \AA$ at 100 (2) K. Cell refinement and data reduction were carried out by Bruker SAINT. SHELXT $[30,31]$ was used to solve structure. The final refinement was carried out by full-matrix least-squares techniques with anisotropic thermal data for nonhydrogen atoms on F. CCDC 1504892 and 1505279 contain the supplementary crystallographic data for this compound can be obtained free of charge from the Cambridge Crystallographic Data Centre via www.ccdc.cam.ac.uk/data_reque st/cif.

\section{Computational details}

The X-ray structure coordinates of the studied thiazoles were used for geometry optimization followed by frequency calculations. For this task, we used Gaussian

Table 1 Viability values and IC $C_{50}$ of thiophenes 6 and 11 against HCT-116 Cell Line

\begin{tabular}{|c|c|c|c|c|c|c|c|c|}
\hline \multirow[t]{2}{*}{ S. no } & \multicolumn{8}{|c|}{ Sample concentration $(\mu \mathrm{g} / \mathrm{mL})$ viability $\%$} \\
\hline & 50 & 25 & 12.5 & 6.25 & 3.125 & 1.56 & 0 & $\begin{array}{l}I C_{50} \\
(\mu g)\end{array}$ \\
\hline Ref. D. & 23.08 & 27.35 & 43.59 & 53.85 & 69.23 & 82.54 & 100 & 5.38 \\
\hline 6 & 39.43 & 58.15 & 79.51 & 86.42 & 92.63 & 96.47 & 100 & 35.9 \\
\hline 11 & 23.81 & 42.96 & 60.34 & 74.89 & 86.93 & 94.57 & 100 & 19.9 \\
\hline
\end{tabular}


03 software [32] and B3LYP/6-31G(d,p) method. All obtained frequencies are positive, and no imaginary modes were detected. GaussView4.1 [33] and Chemcraft [34] programs have been used to extract the calculation results and to visualize the optimized structures.

\section{Cytotoxic activity}

The cytotoxic activity of the synthesized compounds was determined against Human Colon Carcinoma (HCT-116) by the standard MTT assay $[28,29]$.

\section{Conclusions}

Stereoselective synthesis of (Z)-ethyl 2-cyano-2-(4methyl-3-phenylthiazol-2(3H)-ylidene) acetate (6) and its unexpected reaction with DMF-DMA gave (Z)ethyl 2-cyano-2-(5-((E)-3-(dimethylamino)acryloyl)3-phenylthiazol-2(3H)-ylidene)acetate (11). Optimized molecular structures at the B3LYP/6-31G(d,p) level are presented. Thiazole $\mathbf{1 1}$ has more electropositive $\mathrm{S}$-atom than Thiazole 6. The HOMO-LUMO energy gap is lower in the former compared to the latter. The cytotoxic activity of the synthesized thiazoles was evaluated and the results revealed that thiazole derivative $\mathbf{1 1}$ had more activity than thiazole derivative 6 .

\section{Additional file}

Additional file 1: Table S1. The crystal and experimental data of thiazole 6. Table S2. Selected geometric parameters $\left(\AA,{ }^{\circ}\right)$ of thiazole $\mathbf{6}$. Table S3. Hydrogen-bond geometry $\left(\AA,{ }^{\circ}\right)$ of thiazole $\mathbf{6}$. Table S4. The crystal and experimental data of thiazole 11. Table S5. Selected geometric parameters $\left(\AA \AA^{\circ}\right)$ thiazole $\mathbf{1 1}$. Table $\mathbf{S 6}$. Hydrogen-bond geometry $\left(\AA \AA^{\circ}\right)$ thiazole 11. Figure $\mathbf{S 1}$. The atom numbering scheme of the optimized molecular structures of the studied molecules. Table S7. The experimental and calculated geometric parameters of the studied molecules. Table S8. The natural atomic charges of the studied systems using B3LYP method.

\section{Authors' contributions}

YNM, NAK and SSA designed research; MMA, HAG, SMS and WF performed research, analyzed the data, wrote the paper. All authors read and approved the final manuscript.

\section{Author details \\ ${ }^{1}$ Department of Chemistry, College of Science, King Saud University, P. O. Box 2455, Riyadh 11451, Saudi Arabia. ${ }^{2}$ Department of Pharmaceutical Chem- istry, College of Pharmacy, King Saud University, P. O. Box 2457, Riyadh 11451, Saudi Arabia. ${ }^{3}$ Department of Medicinal Chemistry, Faculty of Pharmacy, Uni- versity of Mansoura, Mansoura 35516, Egypt. ${ }^{4}$ Department of Chemistry, Fac- ulty of Science, Cairo University, Giza 12613, Egypt. ${ }^{5}$ Department of Pharma- ceutical Chemistry, Faculty of Pharmacy, King Khalid University, Abha 61441, Saudi Arabia. ${ }^{6}$ Department of Chemistry, Rabigh College of Science and Art, 344, Rabigh 21911, Saudi Arabia. ${ }^{7}$ Department of Chemistry, Faculty of Sci- ence, Alexandria University, P.O. Box 426, Ibrahimia, Alexandria 21321, Egypt. ${ }^{8}$ Institut für Organische Chemie, Universität Stuttgart, Pfaffenwaldring 55, 70569 Stuttgart, Germany.}

\section{Acknowledgements}

The authors extend their sincere appreciation to the Deanship of Scientific Research at the King Saud University for its funding this Prolific Research group (PRG-007).

\section{Competing interests}

The authors declare that they have no competing interests.

\section{Publisher's Note}

Springer Nature remains neutral with regard to jurisdictional claims in published maps and institutional affiliations.

Received: 3 February 2018 Accepted: 26 April 2018

Published online: 11 May 2018

\section{References}

1. Satoh A, Nagatomi Y, Hirata Y, Ito S, Suzuki G, Kimura T, Maehara S, Hikichi H, Satow A, Hata M, Ohta H, Kawamoto H (2009) Discovery and in vitro and in vivo profiles of 4-fluoro-N-[4-[6-(isopropylamino)pyrimidin-4-yl]1,3-thiazol-2-yl]- $N$ - methylbenzamide as novel class of an orally active metabotropic glutamate receptor 1 (mGluR1) antagonist. Bioorg Med Chem Lett 19:5464-5468

2. Siddiqui N, Ahsan W (2011) Synthesis, anticonvulsant and toxicity screening of thiazolyl-thiadiazole derivatives. Med Chem Res 20:261-268

3. Dawane BS, Konda SG, Mandawad GG, Shaikh BM (2010) Poly(ethylene glycol) (PEG-400) as an alternative reaction solvent for the synthesis of some new 1-(4-(4'-chlorophenyl)-2-thiazolyl)-3-aryl-5-(2-butyl-4-chloro$1 \mathrm{H}$-imidazol-5yl)-2-pyrazolines and their in vitro antimicrobial evaluation. Eur J Med Chem 45:387-392

4. Adibpour N, Khalaj A, Rajabalian S (2010) Synthesis and antibacterial activity of isothiazolyloxazolidinones and analogous 3(2H)-isothiazolones. Eur J Med Chem 45:19-24

5. Sondhi SM, Singh N, Lahoti AM, Bajaj K, Kumar A, Lozach O, Meijer L (2005) Synthesis of acridinyl-thiazolino derivatives and their evaluation for anti-inflammatory, analgesic and kinase inhibition activities. Bioorg Med Chem 13:4291-4299

6. Singh N, Bhati SK, Kumar A (2008) Thiazolyl/oxazolylformazanylindoles as potent anti-inflammatory agents. Eur J Med Chem 43:2597-2609

7. Luzina EL, Popov AV (2009) Synthesis and anticancer activity of $\mathrm{N}$-bis(trifluoromethyl)alkyl-N'-thiazolyl and N-bis(trifluoromethyl)alkyl-N'benzo- thiazolylureas. Eur J Med Chem 44:4944-4953

8. lino T, Hashimoto N, Sasaki K, Ohyama S, Yoshimoto R, Hosaka H, Hasegawa T, Chiba M, Nagata Y, Nishimura JET (2009) Structure activity relationships of 3,5-disubstituted benzamides as glucokinase activators with potent in vivo efficacy. Bioorg Med Chem 17:3800-3809

9. Rawal RK, Tripathi R, Katti SB, Pannecouque C, Clercq ED (2008) Design and synthesis of 2-(2,6-dibromophenyl)-3-heteroaryl-1,3-thiazolidin4-ones as anti-HIV agents. Eur J Med Chem 43:2800-2806

10. Shiradkar MR, Akula KC, Dasari V, Baru V, Chiningiri B, Gandhi S, Kaur R (2007) Clubbed thiazoles by MAOS: a novel approach to cyclin-dependent kinase 5/p25 inhibitors as a potential treatment for Alzheimer's disease. Bioorg Med Chem 15:2601-2610

11. Turan-Zitouni G, Chevallet P, Kiliç FS, Erol K (2000) Synthesis of some thiazolyl-pyrazoline derivatives and preliminary investigation of their hypotensive activity. Eur J Med Chem 35:635-641

12. Shih MH, Ke FY (2004) Syntheses and evaluation of antioxidant activity of sydnonyl substituted thiazolidinone and thiazoline derivatives. Bioorg Med Chem 12:4633-4643

13. Kheder NA, Riyadh SM, Asiry AM (2013) Azoles and bis-azoles: synthesis and biological evaluation as antimicrobial and anti-cancer Agents. Chem Pharm Bull 61:504-510

14. Dawood KM, Abdel-Gawad H, Rageb EA, Ellithey M, Mohamed HA (2006) Synthesis, anticonvulsant, and anti-inflammatory evaluation of some new benzotriazole and benzofuran-based heterocycles. Bioorg Med Chem 14:3672-3680

15. Farag AM, Dawood KM, Elmenoufy HA (2004) A convenient route to pyridones, pyrazolo[2,3-a]pyrimidines and pyrazolo[5,1-c]triazines incorporating antipyrine moiety. Heteroat Chem 15:508-514

16. Gomha SM, Kheder NA, Abdelaziz MR, Mabkhot YN, Alhajoj AM (2017) A facile synthesis and anticancer activity of some novel thiazoles carrying 1,3,4-thiadiazole moiety. Chem Cent J 11:25 
17. Mabkhot YN, Alatibi F, El-Sayed NN, Al-Showiman S, Kheder NA, Wadood A, Rauf A, Bawazeer S, Hadda T (2016) Antimicrobial activity of some novel armed thiophene derivatives and petra/osiris/molinspiration (POM) analyses. Molecules 21:222

18. Mabkhot YN, Kheder NA, Barakat A, Choudhary MI, Yousuf S, Frey W (2016) Synthesis, antimicrobial, anti-cancer and molecular docking of two novel hitherto unreported thiophenes. RSC Adv. 6:63724-63729

19. Gomha SM, Kheder NA, Abdelhamid AO, Mabkhot YN (2016) One pot single step synthesis and biological evaluation of some novel Bis(1,3,4thiadiazole) derivatives as potential cytotoxic agents. Molecules 21:1532

20. Mabkhot YN, Alatibi F, El-Sayed NNE, Kheder NA, Al-Showiman SS (2016) Synthesis and structure-activity relationship of some new thiophenebased heterocycles as potential antimicrobial agents. Molecules 21:1036

21. Farag AM, Kheder NA, Mabkhot YN (2009) Synthesis and antimicrobial evaluation of new pyrazole, thiophene, thiazole and 1,3,4-thiadiazole derivatives incorporating pyrimidine ring. Heterocycles 78:1787-1798

22. Kheder NA, Mabkhot YN, Farag AM (2008) Synthesis and antimicrobial evaluation of some new pyrimidine derivatives. Heterocycles 75:887-897

23. Ram VJ, Haque N, Singh SK, Nath M, Shoeb A (1994) Polarized ketene dithioacetals-part ii: synthesis of S, S- and S, N-cyclic ketene dithioacetals and their transformation to azoles and 1,3-dithiole-2-thiones. Phosphorus Sulfur Silicon Relat Elem 88:155-161

24. The crystallographic data for thiazole $\mathbf{6}$ (CCDC 1504892) and thiazole 11 (CCDC 1505279) can be obtained free of charge from the Cambridge Crystallographic Data Center via www.ccdc.cam.ac.uk/data_request/cif
25. Tyson FT, Shaw JT (1952) A new approach to 3-indolecarboxaldehyde. J Am Chem Soc 74:2273-2274

26. Emerson WS, Patrick TM Ju (1952) U.S. Patent 2,581,009, C.A, 46, 9610, 1 Jan 1952

27. Campaigne E, Archer WL (1953) The use of dimethylformamide as a formylation reagent. J Am Chem Soc 75:989-991

28. Mosmann T (1983) Rapid colorimetric assay for cellular growth and survival: application to proliferation and cytotoxicity assays. J Immunol Methods 65:55-63

29. Elaasser MM, Abdel-Aziz MM, El-Kassas RA (2011) Antioxidant, antimicrobial, antiviral and antitumor activities of pyranone derivative obtained from Aspergillus candidus. J Microbiol Biotech Res 1:5-17

30. Sheldrick GM (2008) A short history of SHELX. Acta Crystallogr A 64:112-122

31. Sheldrick GM (1997) SHELXTL-PC (Version 5.1). Siemens Analytical Instruments, Inc., Madison, WI, USA

32. Frisch MJ, Trucks GW, Schlegel HB, Scuseria GE, Robb MA, Cheeseman JR, Montgomery JA Jr, Vreven T, Kudin KN, Burant JC et al (2004) Gaussian-03, Revision C.01. Gaussian Inc, Wallingford, CT, USA

33. Dennington RDII, Keith TA, Millam J (2007) Gauss View, Version 4.1. Semichem Inc, Shawnee Mission, KS, USA

34. Zhurko GA, Zhurko DA (2005) Chemcraft. Lite Version Build 08. Available online: http://www.chemcraftprog.com/. Accessed 1 Apr 2005

\section{Submit your manuscript to a SpringerOpen ${ }^{\odot}$ journal and benefit from:}

- Convenient online submission

Rigorous peer review

- Open access: articles freely available online

- High visibility within the field

- Retaining the copyright to your article

Submit your next manuscript at springeropen.com 